\title{
Complexo teniose-cisticercose: ocorrência em abatedouro de bovinos e conhecimento de estudantes do ensino médio e consumidores no Estado de São Paulo, Brasil*
}

\section{Taeniosis-cysticercosis: occurrence during cattle slaughter and students and consumers knowledge in the Central Region of São Paulo State, Brazil}

\author{
Karina Paes Bürger, ${ }^{* *}$ Pedro Luiz Torres Buzza, ${ }^{* *}$ Edmur Buzza Neto, ${ }^{* *}$ Leonardo Ribeiro dos Santos, ${ }^{* * *}$ \\ Gabriel Augusto Marques Rossi, ${ }^{* \star * *}$ Ana Maria Centola Vidal Martins ${ }^{\star * * * *}$
}

\begin{abstract}
Resumo
O complexo teniose-cisticercose bovina é considerado uma zoonose de grande impacto em saúde pública e animal, que acarreta em importantes perdas econômicas decorrentes da condenação de vísceras e carcaças durante o abate desses animais. O presente trabalho objetivou realizar o diagnóstico de situação do complexo teniose-cisticercose na Região Central do Estado de São Paulo através da determinação da ocorrência da enfermidade em um abatedouro, e também pela avaliação do perfil dos consumidores e do conhecimento de alunos do ensino médio sobre a epidemiologia do complexo teniose-cisticercose. Quanto á ocorrência de cisticercose na região observou-se a frequência de 3,06\% entre os 1.667 bovinos abatidos. Quanto aos consumidores entrevistados, observou-se grande desconhecimento sobre a enfermidade, e também sobre os perigos oriundos do consumo de alimentos de origem desconhecida ou indevidamente preparados. O mesmo desconhecimento foi observado através da aplicação dos questionários aos estudantes. Conclui-se que a região carece de medidas efetivas para o controle da enfermidade, principalmente no tocante à educação da população sobre a importância da enfermidade, seus aspectos epidemiológicos e métodos de prevenção.
\end{abstract}

Palavras-chave: Inspeção Sanitária de Alimentos, Saúde Pública, Taenia saginata, Zoonoses

\begin{abstract}
The bovine taeniosis-cysticercosis complex is considered a zoonosis of major impact on public and animal health, resulting in economic losses resulting from carcasses condemnation during these animals slaughter. This study aimed to perform a diagnosis of the situation of the taeniosis-cysticercosis complex in the Central Region of São Paulo State by establishing the occurrence of the disease in a slaughterhouse, establishing the consumer and profile and high school students knowledge about the disease. There was $3.06 \%$ for cysticercosis in 1.667 cattle slaughtered during the study. About the consumers, it was observed ignorance about the disease, and the risks on the consumption of foods with unknown origin or improperly cooked. The same ignorance was observed in high school students. It can be concluded that the region cares effective measures to control the disease, especially regarding public education about the importance of the disease and prevention.
\end{abstract}

Keywords: Public Health, Sanitary Inspection of Food, Taenia saginata, Zoonosis

\section{Introdução}

No complexo teniose-cisticercose bovina, os humanos são os únicos hospedeiros definitivos de Taenia saginata, albergando a forma adulta do parasita, enquanto os bovinos são os hospedeiros intermediários, que se infectam por meio da ingestão de ovos embrionados, formando cisticercos em sua musculatura. Os animais se infectam ao consumirem água ou pasto contaminados com ovos viáveis do parasita, ou por qualquer outro modo que leve à ingestão desses ovos. Já o homem adquire a teniose pelo consumo de carne crua ou mal passada contendo os cisticercos (SANTOS e BARROS, 2009), sendo um hábito comum em algumas regiões (ESTEVES, 2002).

A ocorrência da cisticercose pode ser determinada pela falta de tratamento dos esgotos urbanos, os quais poluem os mananciais

*Recebido em 27 de abril de 2014 e aceito em 30 de março de 2015.

**Profa. Assistente Doutora, Departamento de Medicina Veterinária Preventiva e Reprodução Animal, Universidade Estadual Paulista "Júlio de Mesquita

Filho", Faculdade de Ciências Agrárias e Veterinárias de Jaboticabal. Autor para correspondência: karinaburger@fcav.unesp.br

${ }^{* * *}$ Médico Veterinário Autônomo

****Pós-graduação (nível doutorado) em Medicina Veterinária, Departamento de Medicina Veterinária Preventiva e Reprodução Animal, Universidade Estadual Paulista "Júlio de Mesquita Filho", Faculdade de Ciências Agrárias e Veterinárias de Jaboticabal.

*****Profa. Assistente Doutora, Departamento de Medicina Veterinária, Universidade de São Paulo, Faculdade de Zootecnia e Engenharia de Alimentos, Pirassununga. 
que irão abastecer os animais e até o próprio homem. A falta de fossas ou coleta de esgoto em algumas áreas permite a contaminação ambiental, sendo comuns os casos em que os animais acabam ingerindo involuntariamente fezes humanas (SANTOS e BARROS, 2009).

Fukuda et al. (2003), utilizando os dados de todos os frigoríficos sob Serviço de Inspeção Federal (SIF) do Estado de São Paulo, evidenciaram uma prevalência média de $4,28 \%$, no período de 1980 a 2001, e verificaram que os animais provenientes do Estado de São Paulo possuíam a maior prevalência, com média de 5,80\%, destacando a importância da necessidade de controle dessa enfermidade para a pecuária nesse estado brasileiro.

A prevenção da enfermidade pode ser realizada através de medidas que atuem no ciclo epidemiológico do parasita, através de saneamento básico, inspeção sanitária de carnes e derivados, combate aos abates clandestinos, redução do consumo de carnes cruas ou mal cozidas e ações de educação sanitária à população.

Em relação ao conhecimento da população da população sobre a enfermidade, poucos trabalhos foram realizados. Entretanto, Manhoso (2003) avaliou o ensino de princípios básicos sobre a enfermidade aferindo o conhecimento de 120 alunos do terceiro ano do ensino médio, de escolas públicas e privadas. $O$ autor verificou que, durante o ensino médio, os alunos que tiveram informações sobre o referido complexo foi $28,34 \%$ dos entrevistados da escola pública, enquanto na privada este valor foi de $98,33 \%$.

Diante desse cenário, o presente trabalho objetivou realizar o diagnóstico de situação do complexo teniose-cisticercose na Região Central do Estado de São Paulo pela avaliação do perfil dos consumidores e do conhecimento de estudantes ensino médio sobre o complexo teniose-cisticercose e da frequência de ocorrência da enfermidade em um abatedouro.

\section{Materiais e Métodos}

Foram inspecionadas 1.667 carcaças de bovinos e as respectivas vísceras no período de julho a agosto de 2008 em um abatedouro-frigorífico na Região Central do Estado de São Paulo sob Serviço de Inspeção Estadual (SISP). A inspeção sanitária das carcaças e vísceras foi realizada de acordo com Brasil (1952), sendo os cisticercos detectados separados em vivos e calcificados, através da inspeção visual. Quando detectadas a presença do parasita, foi registrada a cidade de origem do animal.

Para a avaliação do conhecimento dos consumidores do município, foram aplicados questionários (BRASIL, 1996) a 120 consumidores durante a compra em um supermercado localizado no Município de Descalvado, Estado de São Paulo, durante o primeiro semestre de 2009. Os questionários abrangiam as características do hábito de consumo dos entrevistados e de alguns fatores de risco para ocorrência da infecção pela teniose em humanos

Para avaliação do conhecimento de alunos do ensino médio no Município de Descalvado, Estado de São Paulo, foi aplicado questionários (BRASIL, 1996) em 728 alunos do ensino médio de escolas públicas e privadas, durante o primeiro semestre de
2009. Esta amostragem foi dividida em dois grupos, em que 72 alunos eram de escola privada e 656 eram de escola pública. Os questionários abrangiam o conhecimento sobre a doença e as características do ciclo epidemiológico do parasita, com enfoque nas práticas de prevenção para a enfermidade. Posteriormente, os dados foram analisados de forma descritiva e apresentados em tabelas e gráficos.

\section{Resultados e Discussão}

Determinação da frequência da cisticercose bovina em abatedouro-frigorífico

A Tabela 1 apresenta os dados dos animais que foram abatidos em um abatedouro-frigorífico na Região Central do Estado de São Paulo sob Serviço de Inspeção Estadual (SISP), no período de julho a agosto de 2008. Foram abatidos 1.667 bovinos, dos quais $51(3,06 \%)$ apresentaram-se positivos para cisticercose, sendo que $46(2,76 \%)$ apresentaram cisticercos vivos e 5 $(0,30 \%)$ cisticercos calcificados.

Tabela 1: Frequência de cisticercose viva e calcificada em bovinos abatidos em abatedouro-frigorífico da Região Central do Estado de São Paulo

\begin{tabular}{ccc}
\hline Categoria das carcaças & Número de Animais & $\%$ \\
\hline Cisticercos Vivos & 46 & $2,76 \%$ \\
Cisticercos Calcificados & 5 & $0,30 \%$ \\
Ausência de cisticercos & 1.616 & $96,94 \%$ \\
\hline Total Abatido & 1.667 & $100 \%$ \\
\hline
\end{tabular}

Fukuda et al. (2003), utilizando os dados de todos os frigoríficos sob Serviço de Inspeção Federal (SIF) do mesmo estado, evidenciaram prevalência média de $4,28 \%$ no período de 1980 a 2001, valor superior ao observado nesse estudo. Ainda, levantamento feito a partir de dados de um matadouro localizado na região do Município de Promissão, durante os anos de 2005 a 2008, revelou prevalência média de $3,48 \%$ (27.708/795.516) de cisticercose nos animais (MEDEIROS et al., 2011), demonstrando que a ocorrência nesse estado permanece elevada e carece de redução.

Os animais abatidos e com cisticercos vivos vieram de diversas cidades: 21,74\% eram oriundos do Município de São Carlos, $17,39 \%$ de Bariri, 13,04\% de Pederneiras, $10,87 \%$ de Trabiju, $8,69 \%$ de Araraquara, $8,69 \%$ de Ribeirão Bonito, $6,53 \%$ de Américo Brasiliense, 4,35\% de Dourado, 4,35\% de Rio Claro e $4,35 \%$ de Boa Esperança do Sul, conforme observado na Figura 1. Os animais abatidos que apresentaram cisticercos calcificados vieram de três cidades da região: $60 \%$ de Ribeirão Bonito, $20 \%$ de São Carlos e $20 \%$ de Trabiju.

Tais resultados demonstram falhas na cadeia produtiva da carne bovina durante a etapa de criação nas fazendas em diversas cidades do Estado de São Paulo, visto que o controle da enfermidade é possível quando não ocorre o consumo de água ou alimentos contaminados com ovos presentes nas fezes humanas. 


\section{Localidade dos Animais com Cisticercos Vivos}

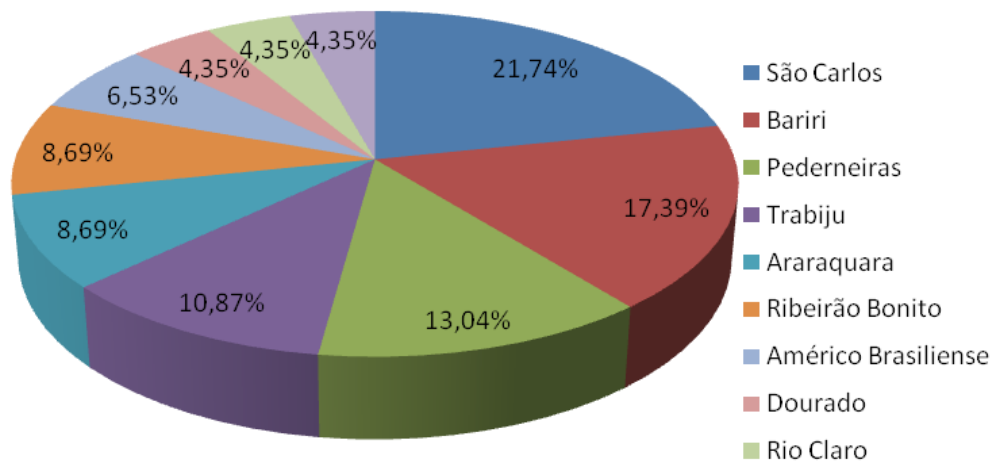

Figura 1: Porcentagem dos casos de cisticercose observada em bovinos abatidos em abatedouro-frigorífico da Região Central do Estado de São Paulo, de acordo com Município de origem.

\section{Avaliação do conhecimento de consumidores}

De um total de 120 consumidores entrevistados nos supermercados, a faixa etária que apresentou maior percentual foi das pessoas com idade entre 21 e 30 anos (38,33\%), seguida pelas pessoas acima de 50 anos $(18,33 \%)$, já os consumidores com idade entre 31 e 50 anos corresponderam a $27,5 \%$, e os indivíduos com até 20 anos representaram 15,83\%.

O nível de escolaridade dos entrevistados que apresentou maior percentual foi dos que cursaram o ensino médio completo $(35,83 \%)$, seguido pelas pessoas que não completaram o ensino médio $(14,17 \%)$. Os que cursaram até o ensino fundamental completo e incompleto ficaram com percentual de $10 \%$ e $8,33 \%$, respectivamente. Os entrevistados que cursaram o ensino superior incompleto e completo foram $8,33 \%$ e $6,7 \%$, respectivamente, e o básico incompleto foi de $11,67 \%$, seguido de $5 \%$ das pessoas que cursaram o ensino básico completo.

Em relação à ocorrência de casos no histórico familiar, foi constatado que o percentual de moradores que já teve solitária foi de $1,67 \%$ e $98,33 \%$ nunca tiveram o parasita diagnosticado. Do total de entrevistados, $75 \%$ nunca ouviram ao mínimo uma vez a expressão "cisticercose" ou "teníase" ou "solitária", enquanto $25 \%$ já ouviram pelo menos vez, demonstrando mais uma vez a necessidade de melhorias em campanhas educativas para a população na região estudada.

O sistema de esgoto em $97,5 \%$ das casas é esgoto público, seguido de apenas $2,5 \%$ em fossa. Sobre o destino dados às fezes produzidas, $77,7 \%$ afirmou destinar ao esgoto público; dentro ou próximo a rios ou mananciais de água foi citado por $15 \%$, enquanto dentro de cisternas foi citado por $7,5 \%$, demonstrando a necessidade de provisão de saneamento básico à população regional, a qual pode estar perpetuando o ciclo da enfermidade.

Conforme pode ser observado na Figura 2, quando perguntado aos entrevistados sobre preferência para o preparo de carne, $64,92 \%$ disseram preferir carne bem passada, $29,11 \%$ disseram gostar de consumir carne cozida, 5,97\% carne mal passada e nenhum entrevistado disse gostar de consumir carne crua.
Os resultados assemelham-se aos de Gai et al. (2003), que relatam uma preferência maior pelo produto bem passado, o que demonstra um dado positivo pois minimiza o risco de transmissão de zoonoses e toxinfecções alimentares, veiculadas por produtos normalmente preparados e/ou servidos impropriamente.

Quanto ao comportamento de compra, 72,99\% dos consumidores relatam comprar a carne em supermercados, $26,28 \%$ compram em açougues e o restante $(0,73 \%)$ em mercearias. Quando perguntados sobre a procedência da carne adquirida, foi observado que $56,67 \%$ não buscam essas informações, podendo as carne serem oriundas de abate clandestino. Isso demonstra a necessidade de educação da população sobre os perigos que podem estar presentes nesses tipos de alimentos comercializados sem fiscalização sanitária e que podem atuar na tranmissão de enfermidades como a teniose.

Figura 2: Porcentagem das respostas obtidas de consumidores do Município de Preferência - Preparo das carnes

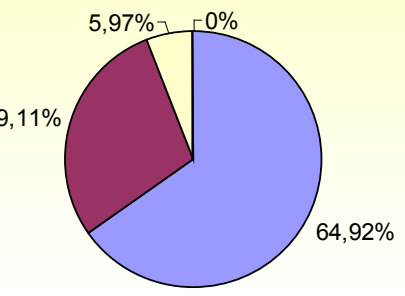

\section{Avaliação do conhecimento de alunos do ensino médio}

Foram interrogados 728 alunos de ensino médio, sendo 72 de escolas privadas e 656 de públicas. Primeiramente, foi questionado se os alunos tiveram informações lecionadas sobre o complexo teniose-cisticercose durante o ensino médio; apenas $17,1 \%$ dos entrevistados da escola pública afirmaram que sim, enquanto na escola particular essa taxa foi de $30,6 \%$. Isso demonstra baixa adoção de políticas públicas de saúde conjuntas com as educacionais, que permitiriam, quando realizadas corretamente, uma possível redução na ocorrência dessa zoonose.

Perguntou-se, também, a respeito do agente etiológico da teniose. Conforme a Figura 3, nas escolas públicas, obervou-se que $25,3 \%$ responderam ser a Taenia solium, 30,3\% a Taenia saginata, $37,3 \%$ disseram ser ambas, e 7,1\% não souberam responder. Já no grupo da escola particular, verificou-se que $25 \%$ elegeram a Taenia solium, 6,9\% a Taenia saginata, 59,7\% que seriam ambas as espécies e $8,4 \%$ não souberam responder. Tais dados alertam para o desconhecimento sobre o agente causador da teniose por parte dos estudantes, demonstrando a necessidade da realização de campanhas educacionais. 


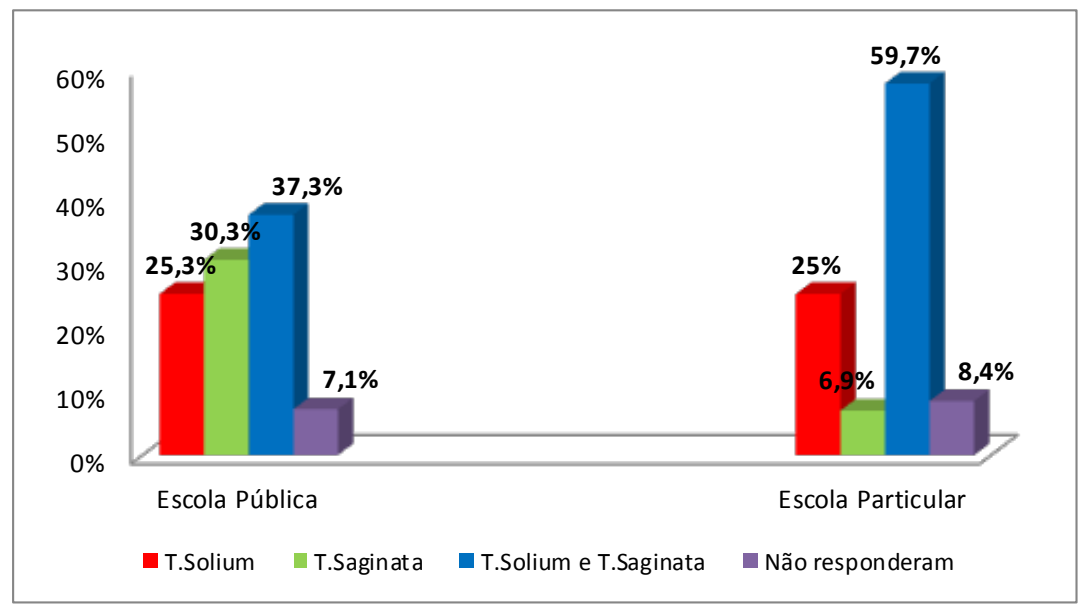

Figura 3: Porcentagem das respostas obtidas de alunos de ensino médio de escolas públicas e privadas referentes ao agente causal da teniose.

Também foi investigado como os entrevistados acreditam que o homem pode adquirir a teniose. Em escolas públicas, constataram-se os seguintes resultados: $8,5 \%$ disseram ser pela ingestão de ovos; $8,5 \%$ pela ingestão de cisticercos; $27,6 \%$ pela ingestão de frutas, verduras e legumes contaminados e $39,3 \%$ pela ingestão de carne mal cozida, com cisticercos. Na escola particular, os dados observados foram: $4,2 \%$ pela ingestão de ovos; $5,5 \%$ pela ingestão de cisticercos; $25 \%$ pela ingestão de frutas, verduras e legumes contaminados e $51,4 \%$ pela ingestão de carnes mal cozidas, com cisticercos.

Notou-se que os alunos das escolas públicas e privadas não conhecem ao certo os riscos que cada alimento possui de acordo com a fase do parasita no complexo teniose- cisticercose, conforme observado na Figura 4, em que apenas aproximadamente metade dos alunos acertou a questão correta.

Em relação ao envolvimento dos animais no ciclo de transmissão do complexo teniose-cisticercose, pode-se observar que na escola pública, $23,8 \%$ escolheram os bovinos, $46,4 \%$ os suínos, $6,7 \%$ os eqüinos, $5,9 \%$ os cães, $3,35 \%$ os gatos e $13,85 \%$ escolheram outras alternativas. Enquanto que na escola privada, $33,3 \%$ optaram pelos bovinos, $40,3 \%$ optaram pelos suínos, $1,4 \%$ optaram pelos eqüinos, $2,8 \%$ optaram pelos cães, ninguém optou pelos gatos e 22,2 optaram por outras alternativas. Notouse que os alunos elegeram os suínos como a principal fonte de transmissão, provavelmente por ser uma crença popular errônea popular que o consumo de carne de suínos é que transmite a cisticercose ao humano.

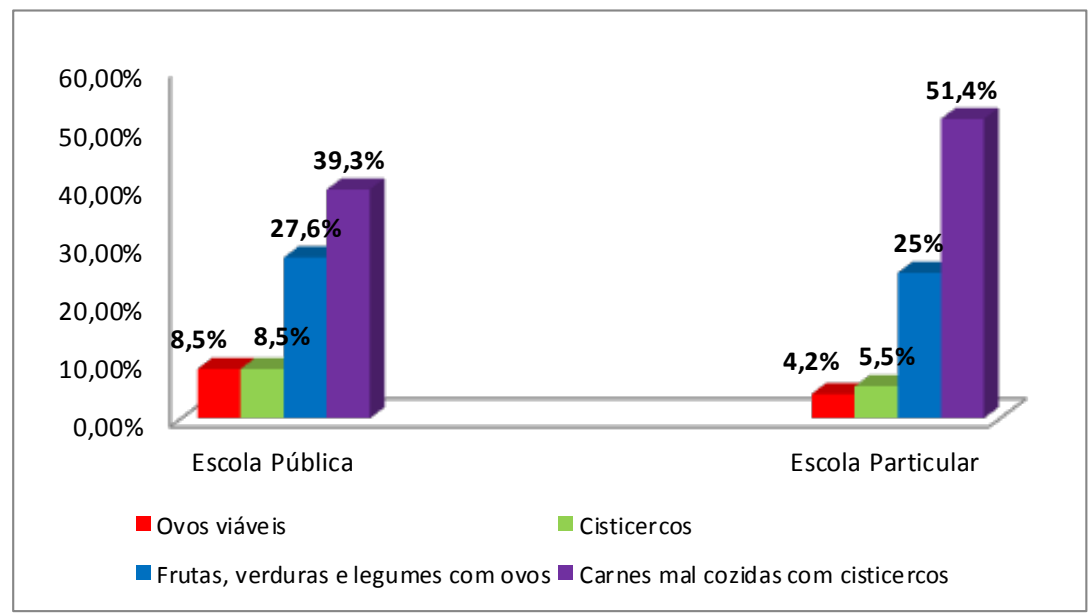

Figura 4: Porcentagem das respostas obtidas de alunos de ensino médio de escolas públicas e privadas referentes a via de transmissão da teniose.

\section{Conclusões}

$\mathrm{Na}$ Região Central do Estado de São Paulo foi observada a presença de cisticercos em $3.06 \%$ dos bovinos avaliados, e grande desconhecimento da população, tanto os consumidores quanto os estudantes do ensino médio sobre o tema, evidenciando um sério problema de saúde pública. Assim, a Região Central do Estado de São Paulo carece de medidas efetivas para o controle do complexo teniose-cisticercose, principalmente no tocante a educação da população sobre a importância da enfermidade e métodos de prevenção. 


\section{Referências}

BRASIL. FUNASA - FUNDAÇÃO NACIONAL DA SAÚDE. Projeto para o controle do complexo teníase/cisticercose no Brasil. Brasília: FUNASA, 54p, 1996.

BRASIL. Ministério da Agricultura Pecuária e Abastecimento. Regulamento da Inspeção Industrial e Sanitária dos Produtos de Origem Animal (RIISPOA), Diário Oficial da União, Brasília, 29 de março de 1952.

DUARTE, E. R.; ALMEIDA, A. C.; CABRA, B. L.; ABRÃO, F. O.; OLIVEIRA, L. N.; FONSECA, M. P. da; SAMPAIO, R. A. Análise da contaminação parasitária em compostos orgânicos produzidos com biossólidos de esgoto doméstico e resíduos agropecuários. Ciência Rural, v.38, n.5, p.1279-121285, 2008.

FUKUDA, R. T.; PRATA, L. F.; VERARDINO, H.; ALMEIDA, L. A. M. Evolução da cisticercose bovina em animais abatidos no Estado de São Paulo. Revista Higiene Alimentar, São Paulo, v.17, n.108, p.21-31, 2003.

GAI, Z. T. et al. Perfil do consumidor de carnes da cidade de Campos dos Goytacazes/RJ. Revista Higiene Alimentar, v. 17, n. 104/105, p. 17-18, 2003.
MANHOSO, F. F. R. Cisticercose bovina: aspectos epidemiológicos e perfil educacional do consumidor na região oeste do Estado de São Paulo. 2003. 57 f. Tese (Doutorado em Medicina Veterinária) - Faculdade de Ciências Agrárias e Veterinárias, Universidade Estadual Paulista, Jaboticabal, 2003. MEDEIROS, E. S.; OLIVEIRA, J. T. F. de; PORTO, W. J. N.; PINHEIRO JÚNIOR, J. W.; SOARES, K. D. A.; ALVES, L. C. Prevalência da cisticercose em um matadouro sob inspeção federal no Município de Promissão no Estado de São Paulo. In: V Congresso Latino Americano e XI Congresso de Higienistas de Alimentos, Salvador, Bahia. 2011. Anais.. Disponível em: http:// www.sovergs.com.br/site/higienistas/trabalhos/10363.pdf, Acesso em 09 jan. 2013.

SANTOS, J. M. G.; BARROS, M. C. R. B. Endoparasitas de Importância no Comércio da Carne, Revista em Agronegócio e Meio Ambiente, v.2, n.1, p.21-39, 2009.

SILVA, A. V. M. Teníase e cisticercose, In: NEVES, D. P.et al. 11. ed. Parasitologia humana. São Paulo: Atheneu,2005. cap. 25, p. 227-237. 